\title{
O desafio macroeconômico de 2015-2018
}

\author{
NELSON BARBOSA FILHO
}

RESUMO: Este artigo apresenta uma perspectiva macroeconômica do Brasil no final de 2014 e uma análise dos principais desafios à sua política macroeconômica nos anos subsequentes. De um lado, a análise é focada na relação entre as taxas de juros, o crescimento e a taxa de câmbio real. Por outro lado, o documento também analisa os múltiplos aspectos e problemas da política fiscal no Brasil.

PALAVRAS-CHAVE: Brasil; política macroeconômica.

ABSTRACT: The macroeconomic challenge for 2015-2018. This paper presents a macroeconomic outlook of Brazil at the end of 2014 and an analysis of the main challenges to its macroeconomic policy in the subsequent years. On one side, the analysis is focused on the relationship between interest rates, growth and the real exchange rate. On the other, the paper also analyzes the multiples aspects and problems of fiscal policy in Brazil.

KEYWORDS: Brazil; macroeconomic; policy.

JEL Classification: E60; N16.

A economia brasileira passa por um período de lento crescimento do PIB e inflação ainda elevada. Esta fase começou em 2012 - quando nossos termos de troca começaram a cair e nossa taxa de câmbio começou a subir - devido às mudanças das condições econômicas internacionais. Do ponto de vista teórico, a combinação de desaceleração da produção com aceleração de preços geralmente ocorre após um choque de oferta adverso. Há evidências de que este tipo de choque ocorreu no Brasil nos últimos três anos. Houve aumento substancial dos preços dos alimento em 2012 e forte depreciação cambial em 2012 e 2013. Porém, apesar desses choques adversos, também há evidências de que a desaceleração do PIB tem causas internas. Nos últimos anos, houve queda da rentabilidade esperada em investimentos de longo prazo, aumento da incerteza macroeconômica sobre a evolu-

\footnotetext{
* Professor titular da Escola de Economia de São Paulo da FGV, do IE/UFRJ e Pesquisador do IBRE/ FGV. Todas as opiniões e eventuais erros contidos neste texto são de responsabilidade do autor. E-mail: nelson.barbosa@fgv.br. Texto preparado para a sessão "Qual é a variável macroeconômica prioritária no processo de ajuste?", do $10^{\circ}$ Fórum de Economia da Escola de Economia de São Paulo (EESP/FGV), em 15 e 16 de setembro de 2014. Submetido: 18/agosto/2014; Aprovado: 12/setembro/2014.
} 
ção da taxa de juros e da política fiscal, desaceleração da oferta de crédito livre e redução da taxa de crescimento dos salários reais. Do lado positivo, a taxa de desemprego caiu e o processo de inclusão social continuou, com redução da pobreza e diminuição da desigualdade da distribuição de renda, mesmo num contexto de crescimento mais lento da economia.

O atual debate político e econômico já produziu e certamente ainda produzirá muitas análises sobre nosso desempenho macroeconômico recente. Uma análise mais detalhada da economia brasileira nos últimos anos está fora do escopo deste artigo e pode ser encontrada em outros trabalhos ${ }^{1}$. Devido ao foco macroeconômico deste Fórum, eu me concentrarei nos principais desafios para superação da atual conjuntura de lento crescimento e inflação ainda elevada.

Minha proposição central é que o próximo governo, seja ele qual for, enfrentará dois grandes desafios macroeconômicos: um cambial e outro fiscal. O desafio cambial é tornar o sistema de metas de inflação menos dependente da apreciação recorrente do real (BRL), que tem dificultado a diversificação produtiva e o desenvolvimento da economia brasileira no médio prazo. O desafio fiscal é aumentar o resultado primário recorrente do setor público num contexto em que também é necessário atender às demandas crescentes da população sobre o Estado sem aumentar a carga tributária.

Minha principal conclusão é que a superação dos dois desafios mencionados passa, inevitavelmente, pela maior liberalização dos preços relativos da economia — incluindo a taxa de câmbio real e as tarifas de concessões — para aumentar a competitividade das empresas e recuperar a atratividade dos investimentos privados. A superação dos desafios cambial e fiscal com responsabilidade social também requer o direcionamento do espaço fiscal do governo para a continuidade do processo de inclusão social, ampliando tal iniciativa para a oferta de serviços públicos universais de melhor qualidade, além das transferências de renda.

\section{O DESAFIO CAMBIAL}

No início do governo Dilma, a taxa de câmbio real efetiva estava no nível mais baixo desde o Plano Real. Naquele momento não havia espaço para uma apreciação adicional do BRL sem comprometer a estabilidade e o desenvolvimento da economia no médio prazo. Diante desse quadro, o governo adotou uma série de medidas para evitar a apreciação adicional do BRL, via regulação de fluxos de capitais com IOF, e aumentar a competitividade da indústria, via incentivos fiscais e financeiros numa "desvalorização fiscal".

A apreciação excessiva do BRL no início de 2011 foi resultado de um processo longo, que começou logo após as eleições de 2002. Em linhas gerais ele pode ser dividido em três fases (Figura 1):

\footnotetext{
${ }^{1}$ Para visões diferentes, ver Barbosa Filho (2012) e Giambiagi e Schwartzman (2014).
} 
Figura 1: Taxa de Câmbio Real (índice, jun/94=100)

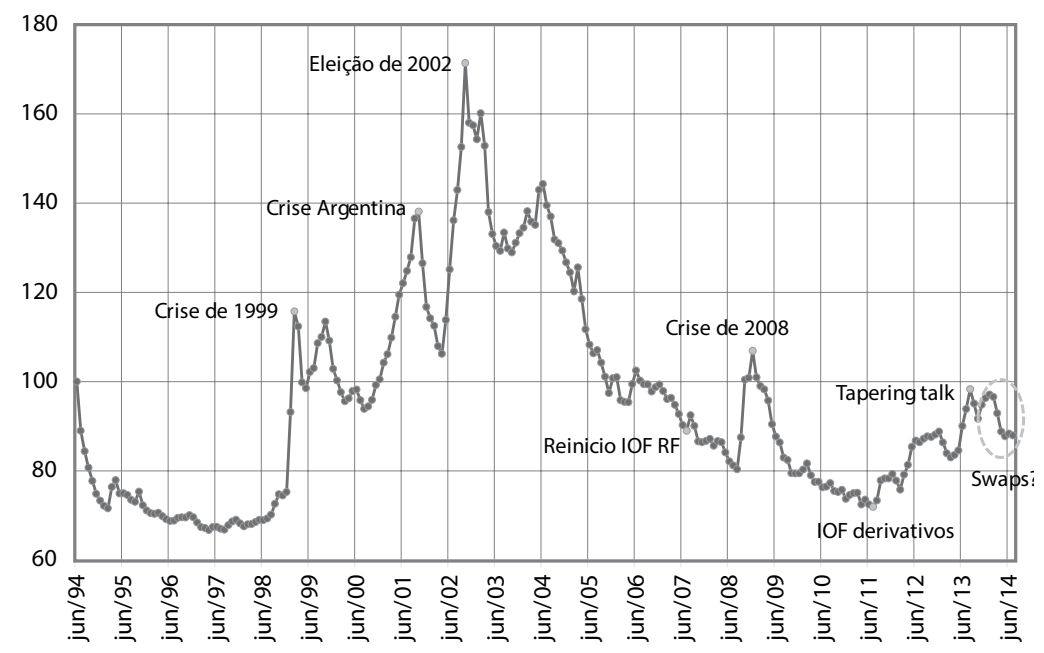

Fonte: BCB e elaboração do autor.

i. Uma fase de correção cambial, de 2003 a 2005, quando a apreciação do BRL basicamente eliminou a depreciação rápida e substancial ocorrida nos anos anteriores. No final do período, a taxa de câmbio real havia retornado ao patamar verificado antes da crise argentina, que por sua vez era muito próximo ao valor verificado antes do Plano Real.

ii. Uma fase de apreciação e crise, de 2006 a 2008, quando o boom nos preços internacionais de commodities reduziu a taxa de câmbio real para um valor próximo ao verificado durante o Plano Real. Esse período terminou com a crise financeira de 2008, que depreciou as moedas de economias emergentes e recolocou a taxa de câmbio real temporariamente no patamar verificado no final de 2005 .

iii. Uma fase de apreciação e intervenção, de 2009 a 2011, quando a expansão da liquidez mundial gerou outro boom dos preços internacionais de commodities e empurrou a taxa de câmbio real novamente para o nível verificado no final do Plano Real. Esse período terminou no início do governo Dilma, quando o governo brasileiro introduziu um imposto sobre o aumento de posição vendida em BRL no mercado de derivativos cambiais (o "IOF derivativos") para impedir uma apreciação ainda maior do BRL.

A situação cambial mudou a partir de 2012, quando o BRL começou a se depreciar sem grandes intervenções por parte do governo brasileiro devido ao novo cenário econômico internacional. Mais especificamente, em 2012, a desaceleração do crescimento econômico mundial - especialmente da China — reduziu os termos de troca do Brasil e depreciou o BRL. No ano seguinte, a expectativa de redução dos estímulos monetários por parte do Federal Reserve dos EUA - o “tapering talk" de Ben Bernanke - gerou uma nova depreciação cambial no Brasil. 
Considerando os dois anos, a taxa de câmbio real subiu aproximadamente $21 \%$ entre dezembro de 2011 e dezembro de 2013. Na história econômica brasileira, uma depreciação cambial desta magnitude tem um impacto recessivo e inflacionário sobre a economia, funcionando como um choque de oferta adverso.

A forte depreciação do BRL levou o governo brasileiro a reverter sua estratégia cambial a partir de 2013, passando do combate à apreciação ao combate à depreciação². Mais especificamente, no final de 2013 o Ministério da Fazenda (MF) retirou a maior parte de sua tributação sobre entrada de capitais e apostas na apreciação do BRL, enquanto o Banco Central do Brasil (BCB) passou a oferecer proteção financeira (hedge) contra a depreciação do BRL via swaps cambiais no mercado de derivativos (Figura 2) 3 $^{3}$. Até meados de 2014 o BCB já havia ofertado em hedge cambial o equivalente a $25 \%$ das reservas cambiais brasileiras em dólares norte-americanos (USD). Apesar de o resultado dos swaps ser pago ou recebido em BRL, eles representam uma diminuição da proteção líquida do governo brasileiro contra uma depreciação do $\mathrm{BRL}^{4}$.

Figura 2: Reservas Internacionais

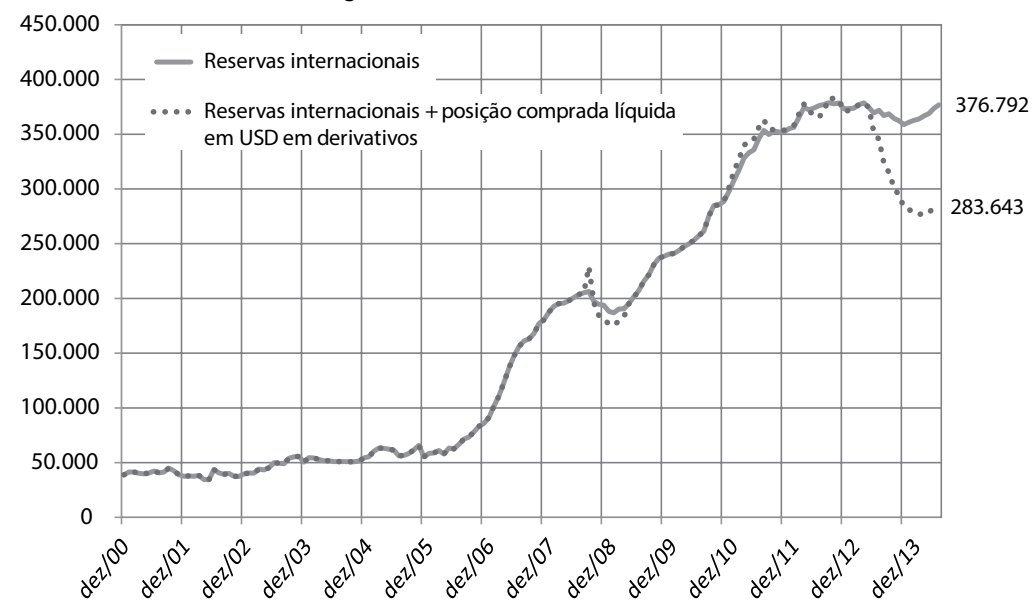

Ao oferecer um valor substancial de hedge cambial ao mercado, o BCB contribuiu para a reversão de mais de um terço do ajuste da taxa de câmbio real ocorrida entre dezembro de 2012 e dezembro de 2013. Em números, a taxa de câmbio real do Brasil caiu 8\% entre dezembro de 2013 e julho de 2014. Caso a taxa de câmbio real tivesse permanecido no valor verificado antes do Plano Real, que por

\footnotetext{
${ }^{2}$ Cabe assinalar que esta reversão marca uma mudança importante de política, pois até 2012 o governo brasileiro enfatizava os perigos de "guerras cambiais" por parte dos países avançados.

${ }^{3}$ Para os detalhes deste contrato, ver o "contrato de swap cambial com ajuste periódico baseado em operações compromissadas de um dia", disponível no site da BMF Bovespa.

${ }^{4}$ Por exemplo, com base nos valores de julho de 2014, caso o BRL se depreciasse em 10 centavos, o BCB teria um ganho patrimonial de $\mathrm{R} \$ 37,7$ bilhões devido a suas reservas, e uma perda de $\mathrm{R} \$ 9,3$ bilhões com swaps cambiais.
} 
sua vez é muito próximo ao seu valor em agosto de 2013, a taxa de câmbio nominal BRL/USD teria sido de 2,51 em vez de 2,23 em julho de 2014 (Figura 3).

Figura 3: Taxa de Câmbio Nominal (TCN) e Taxas

de Câmbio Nominal Ajustadas (TCNA)

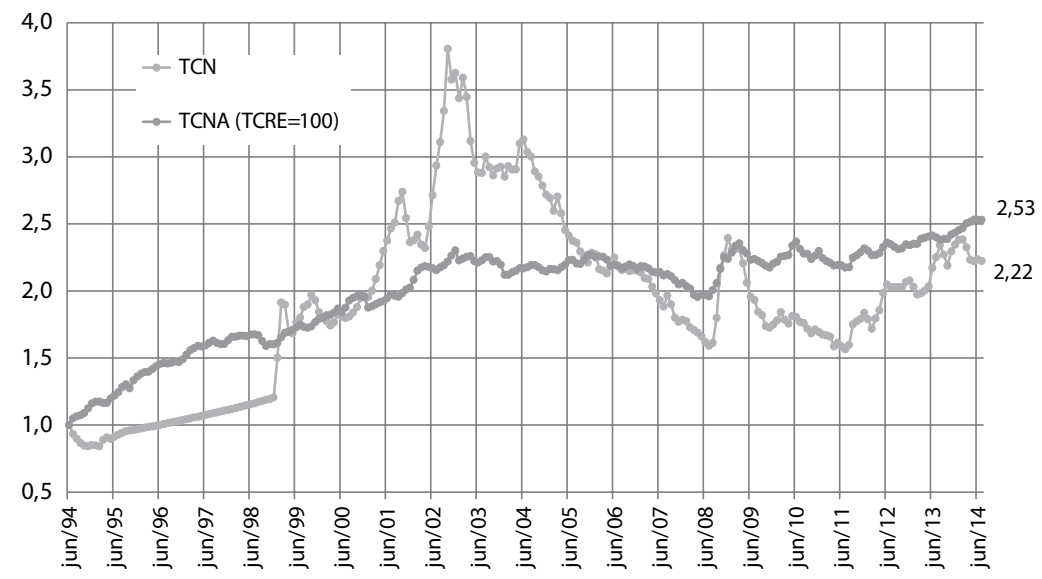

Fonte: BCB e elaboração do autor.

Mas a apreciação recente do BRL não resulta apenas da venda de swaps pelo BCB. A sinalização de que a retirada dos estímulos monetários e uma eventual elevação da taxa de juros nos EUA seria lenta - o "forward guidance" de Janet Yellen - também contribuiu para a apreciação do BRL no início deste ano. Em linhas gerais, a tendência de longo prazo da taxa de câmbio brasileira depende muito mais das condições financeiras internacionais do que da atuação do BCB ou do MF. Porém, no curto prazo, as autoridades econômicas podem acelerar ou adiar os ajustes da taxa de câmbio real mediante intervenções quantitativas e regulatórias no mercado do câmbio. Do ponto de vista teórico, essas intervenções têm por objetivo suavizar os ajustes — reduzir a volatilidade cambial — pois essa é uma das funções da política macroeconômica. Na prática, em momentos de depreciação, as intervenções do governo brasileiro têm procurado adiar ou mesmo impedir o ajuste da taxa de câmbio para não comprometer o combate à inflação.

Cabe destacar que o "medo de depreciar" das autoridades econômicas brasileiras não depende da orientação partidária ou ideológica do governo, mas sim da alta correlação entre variação cambial e controle da inflação no Brasil ${ }^{6}$. Mais especificamente, mesmo depois da adoção do câmbio flutuante, em 1999, a política monetária brasileira ainda depende excessivamente da variação da taxa de câmbio para o cumprimento das metas de inflação. Para ilustrar este ponto, vale a pena

\footnotetext{
${ }^{5}$ Considerando a taxa média de venda BRL/USD.

${ }^{6}$ A referência clássica sobre o "medo de flutuar" é Calvo e Reinhart (2000). No caso do Brasil e de outros países latino-americanos, o medo maior é de depreciar, não de apreciar.
} 


\begin{tabular}{|c|c|c|c|c|c|c|c|c|c|c|c|c|c|c|c|c|}
\hline 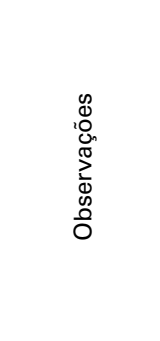 & 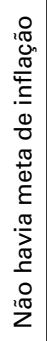 & 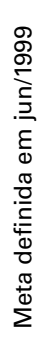 & 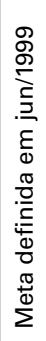 & 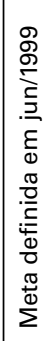 & 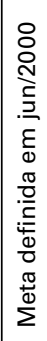 & 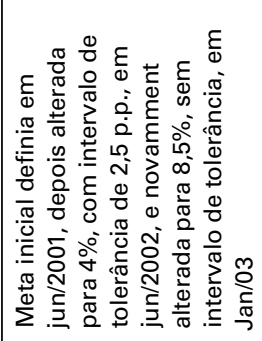 & 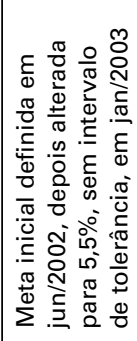 & 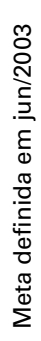 & 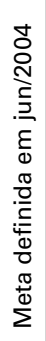 & 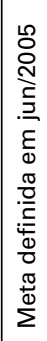 & 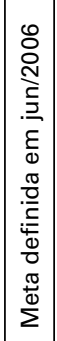 & 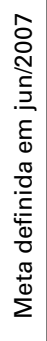 & 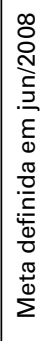 & 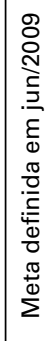 & 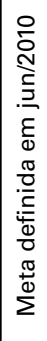 & 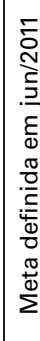 \\
\hline 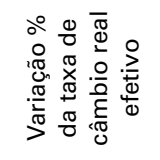 & 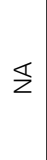 & $\begin{array}{l}\infty \\
\infty \\
\stackrel{\rho}{\gamma}\end{array}$ & $\frac{m}{\infty}$ & $\stackrel{m}{\stackrel{m}{+}}$ & \begin{tabular}{l}
\multirow{f}{f}{} \\
$\stackrel{0}{\circ}$
\end{tabular} & స్ & $\stackrel{\bar{T}}{i}$ & 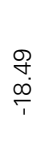 & \begin{tabular}{l}
$\stackrel{0}{\Theta}$ \\
$\stackrel{0}{\circ}$ \\
\hdashline
\end{tabular} & $\stackrel{\substack{i \\
i}}{ }$ & $\left|\begin{array}{l}\stackrel{N}{\sim} \\
\stackrel{i}{i}\end{array}\right|$ & $\begin{array}{l}\hat{0} \\
\dot{0}\end{array}$ & $\begin{array}{l}8 \\
\stackrel{\infty}{N} \\
\stackrel{1}{T}\end{array}$ & $\begin{array}{l}\stackrel{\leftrightarrow}{\leftrightarrow} \\
\stackrel{i}{i}\end{array}$ & $\stackrel{\infty}{\stackrel{\infty}{\check{c}}}$ & $\begin{array}{l}\widehat{c} \\
0 \\
0\end{array}$ \\
\hline 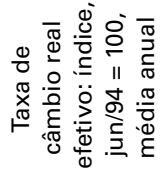 & 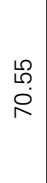 & $\begin{array}{l}\underset{N}{N} \\
\stackrel{0}{0}\end{array}$ & $\stackrel{\cong}{\stackrel{n}{\sigma}}$ & 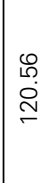 & $\stackrel{\stackrel{g}{\rightleftharpoons}}{\stackrel{m}{m}}$ & 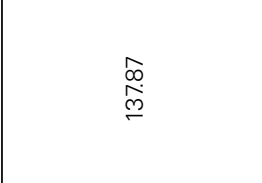 & 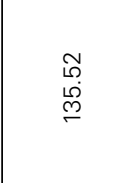 & $\begin{array}{l}\text { f. } \\
\stackrel{0}{\circ}\end{array}$ & $\begin{array}{l}\stackrel{2}{2} \\
\infty \\
\infty\end{array}$ & $\begin{array}{l}8 \\
\dot{\sigma}\end{array}$ & $\mid \begin{array}{l}\circ \\
\check{\Omega} \\
\infty\end{array}$ & $\begin{array}{l}\bar{L} \\
\infty \\
\infty\end{array}$ & 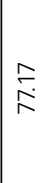 & Е & $\begin{array}{l}m \\
m \\
\dot{\infty}\end{array}$ & ㅎ. \\
\hline 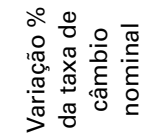 & $\Sigma$ & $\begin{array}{l}\hat{n} \\
\dot{0} \\
ம\end{array}$ & $\begin{array}{l}\stackrel{L}{\infty} \\
\infty \\
0 \\
0\end{array}$ & 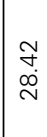 & $\begin{array}{l}\stackrel{\infty}{\sim} \\
\stackrel{+}{\sim}\end{array}$ & 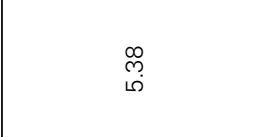 & $\begin{array}{l}\stackrel{\llcorner}{\circ} \\
\stackrel{+}{+}\end{array}$ & $\begin{array}{l}\hat{N} \\
\dot{0} \\
+1\end{array}$ & 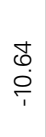 & 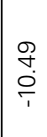 & 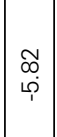 & $\begin{array}{l}\infty \\
\infty \\
\infty \\
\infty\end{array}$ & $\begin{array}{l}\mathscr{D} \\
\infty \\
\stackrel{+}{\mp}\end{array}$ & $\begin{array}{l}\text { ¿ } \\
\stackrel{+}{+}\end{array}$ & $\begin{array}{l}9 \\
6 \\
0 \\
6\end{array}$ & $\begin{array}{l}\stackrel{\circ}{m} \\
\stackrel{0}{\circ}\end{array}$ \\
\hline 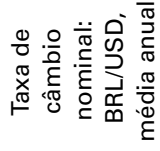 & $\stackrel{\oplus}{\rightleftharpoons}$ & $\stackrel{\infty}{+}$ & $\stackrel{\substack{\infty \\
\infty}}{\stackrel{\infty}{\leftarrow}}$ & 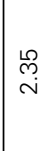 & $\begin{array}{l}\tilde{N} \\
\text { N }\end{array}$ & $\begin{array}{l}\infty \\
\stackrel{\infty}{\infty} \\
\dot{m}\end{array}$ & 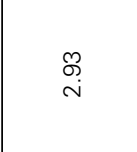 & 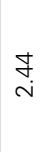 & $\stackrel{\infty}{\stackrel{\infty}{i v}}$ & $\stackrel{\stackrel{\leftrightarrow}{\leftrightarrow}}{\leftarrow}$ & $\stackrel{\infty}{\infty}$ & $\stackrel{8}{\mathrm{i}}$ & $\stackrel{\rho}{\stackrel{\rho}{\leftarrow}}$ & $\stackrel{\widehat{o}}{r}$ & 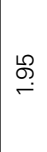 & $\stackrel{0}{\stackrel{n}{i}}$ \\
\hline 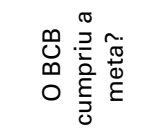 & 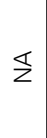 & $\sum_{\mathfrak{\omega}}$ & $\sum_{\infty}$ & 是 & 是 & 是 & 是 & $\sum_{\infty}$ & $\sum_{\infty}$ & $\sum_{\infty}$ & $\sum_{\infty}$ & $\sum_{\sim}$ & $\sum_{\infty}$ & $\sum_{\omega}$ & $\sum_{\infty}$ & $\frac{\sum}{\omega}$ \\
\hline 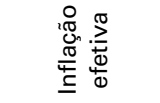 & $\begin{array}{l}\stackrel{\leftrightarrow}{\leftrightarrow} \\
\leftarrow\end{array}$ & $\begin{array}{l}\text { के } \\
\infty\end{array}$ & $\begin{array}{l}\hat{\sigma} \\
\text { مे }\end{array}$ & 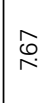 & 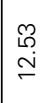 & ले & 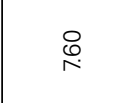 & 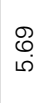 & $\underset{\oplus}{\stackrel{\nabla}{m}}$ & 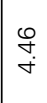 & $\mid \begin{array}{c}8 \\
\qquad \\
\circ\end{array}$ & 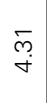 & 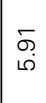 & $\begin{array}{l}\text { 유 } \\
0\end{array}$ & 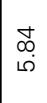 & Бூ \\
\hline 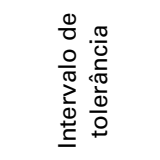 & $\Sigma$ & ì & ¿ & $\stackrel{\text { O }}{\text { i }}$ & $\begin{array}{l}8 \\
\text { i }\end{array}$ & $\stackrel{8}{\text { i }}$ & $\begin{array}{l}\text { م } \\
\text { N }\end{array}$ & م̊ & $\stackrel{\text { O }}{\text { i }}$ & O & 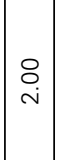 & $\begin{array}{l}8 \\
\text { ì }\end{array}$ & O & $\stackrel{\text { i }}{\text { i }}$ & O & $\stackrel{\circ}{\circ}$ \\
\hline 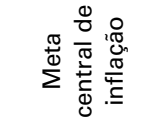 & $\S$ & $\begin{array}{l}8 \\
\infty \\
\infty\end{array}$ & $\begin{array}{l}8 \\
0 \\
0\end{array}$ & $\underset{+}{\stackrel{8}{\circ}}$ & $\begin{array}{l}\stackrel{\rho}{\circ} \\
\text { ल) }\end{array}$ & $\stackrel{\llcorner}{\stackrel{\sim}{m}}$ & $\begin{array}{l}\stackrel{L}{\stackrel{2}{m}} \\
\dot{m}\end{array}$ & 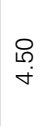 & $\begin{array}{l}\stackrel{\rho}{\circ} \\
+ \\
+\end{array}$ & 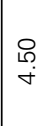 & $\mid \begin{array}{l}\circ \\
\stackrel{\leftrightarrow}{+} \\
\forall\end{array}$ & $\begin{array}{l}\stackrel{\circ}{\circ} \\
\stackrel{+}{+}\end{array}$ & 号 & $\begin{array}{l}\stackrel{\circ}{\circ} \\
\stackrel{+}{*}\end{array}$ & 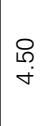 & 只 \\
\hline \multirow[t]{2}{*}{$\stackrel{\circ}{\frac{c}{<}}$} & $\begin{array}{l}\infty \\
\stackrel{\infty}{\circ} \\
\stackrel{\sigma}{\circ}\end{array}$ & ஜே & ঃ & ঠ্ণ & ర్ & ஜ̊ำ & ষ্ণ & $\stackrel{\text { 오 }}{\stackrel{\circ}{N}}$ & $\begin{array}{l}\stackrel{8}{ } \\
\stackrel{人}{ }\end{array}$ & 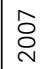 & $\begin{array}{l}\infty \\
\stackrel{\sim}{\circ} \\
\stackrel{N}{2}\end{array}$ & $\stackrel{8}{\circ}$ & 음 & $\bar{\delta}$ & $\underset{\sim}{\sim}$ & $\stackrel{m}{i}$ \\
\hline & 0 & - & $\sim$ & $m$ & 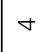 & مـ & 0 & $\wedge$ & $\infty$ & $\sigma$ & 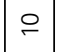 & $=$ & $\cong$ & $\stackrel{M}{\square}$ & $\underset{\leftarrow}{\Xi}$ & $\stackrel{\llcorner}{\square}$ \\
\hline
\end{tabular}


comparar a inflação efetiva com a meta de inflação estabelecida com maior prazo de antecedência (normalmente de 18 meses) pelo governo. Os dados da economia brasileira indicam que (Tabela 1 ):

(i) O BCB cumpriu a meta de inflação em onze dos quinze anos desde a adoção do sistema de metas de inflação, em 1999 (73\% de sucesso).

(ii) Houve redução da taxa de câmbio real em oito dos onze anos nos quais o BCB cumpriu a meta de inflação ( $72 \%$ dos casos de sucesso).

(iii) Houve redução da taxa de câmbio nominal BRL/USD em seis dos onze anos nos quais o BCB cumpriu a meta de inflação ( $55 \%$ dos casos de sucesso).

A importância da variação cambial para o cumprimento do sistema de metas de inflação é ainda maior do que transparece acima se nós considerarmos que os três casos de cumprimento da meta de inflação com aumento da taxa de câmbio real ocorreram em condições bem especiais. Mais especificamente:

(i) Em 1999 o BCB cumpriu a meta de inflação, apesar da depreciação do BRL, porque foi o primeiro ano do sistema de metas de inflação. A meta foi estabelecida em junho, num valor elevado ( $8 \%$ ), quando já se conhecia praticamente $50 \%$ da inflação do ano.

(ii) Em 2012 e 2013, o BCB novamente cumpriu a meta de inflação, apesar da depreciação do BRL, devido à ajuda do resto do governo no controle de preços administrados. Houve suavização do aumento dos preços dos combustíveis via corte de impostos (CIDE) em 2012, e redução dos preços da energia elétrica, em 2013. Além disso, em 2013 também houve uma redução atípica da inflação de transporte urbano - devido às manifestações populares de junho daquele ano - e uma nova suavização do ajuste nos preços dos combustíveis, desta vez por parte da Petrobras.

A forte influência da taxa de câmbio sobre a inflação brasileira acabou gerando um padrão recorrente de atuação por parte do $\mathrm{BCB}$, no qual a autoridade monetária tende a tolerar uma apreciação, mas a lutar contra uma depreciação do BRL. O resultado deste viés de política monetária é uma tendência recorrente de apreciação cambial, isto é, uma sucessão de "miniciclos" de apreciação gradual e depreciação súbita do BRL, em torno da tendência de longo prazo da taxa de câmbio real determinada pelas condições financeiras internacionais.

Nos miniciclos especulativos apontados acima, a apreciação gradual do BRL ocorre via operações de arbitragem entre as taxas de juros domésticas e internacionais (carry trade), até que a taxa de câmbio real caia para um nível tão baixo que faz com que a maioria do mercado espere uma depreciação do BRL. Uma vez atingido esse ponto, a depreciação cambial ocorre após um choque exógeno - interno ou externo - que eleva rapidamente a taxa de câmbio real até que o $\mathrm{BCB}$ inicie uma nova fase de apreciação cambial via elevação de sua taxa básica de juros.

Com base na visão acima, o desafio cambial de 2015-2018 é tornar o controle da inflação menos dependente da taxa de câmbio, de modo a evitar a apreciação excessiva do BRL. Ao invés de tolerar apreciações e combater depreciações, a política monetária brasileira deve ser consistente com uma taxa de câmbio real estável 
e favorável ao aumento do investimento e da produtividade do trabalho ${ }^{7}$. Em outras palavras, é necessário eliminar ou pelo menos diminuir os miniciclos de apreciação e depreciação cambial induzidos pela política monetária brasileira.

Obviamente, o valor da taxa de câmbio real não depende somente da política monetária, mas também do restante da política macroeconômica, sobretudo da política fiscal, bem como da evolução das regras ou instituições que determinam o funcionamento dos mercados. Devido ao foco macroeconômico deste artigo, eu não abordarei em questões microeconômicas em minha análise. Na próxima seção nós analisaremos a política fiscal. Para concluir esta seção, vejamos por que é necessário eliminar ou reduzir a tendência da política monetária em apreciar recorrentemente o BRL.

Em primeiro lugar, considere a relação entre taxa de câmbio real e inflação no curto prazo. Um aumento da taxa de câmbio tem um impacto inflacionário temporário devido à elevação dos preços das importações. Estudos sobre o Brasil indicam que o "pass-through" do câmbio para os preços ao consumidor é de $5 \%$ a $10 \%$, dependendo do ajuste ou não dos preços dos combustíveis. O efeito total do câmbio tende a ocorrer num período de 18 meses, ou seja, dada uma depreciação do BRL, a inflação sobe no curto prazo. Porém, à medida que a taxa de câmbio real se estabiliza num novo patamar, o impacto inflacionário da depreciação cessa e a inflação cai no médio prazo.

Em segundo lugar, o nível no qual a taxa de câmbio real se estabiliza também é importante para o funcionamento da economia, pois ele altera o crescimento do PIB, o balanço de pagamentos e a taxa de inflação de longo prazo. Em outras palavras, além do "pass-through" de curto prazo, há três relações importantes entre o nível da taxa de câmbio real e o desenvolvimento econômico em países de renda média como o Brasil:

(i) Câmbio e conta-corrente: quanto maior a taxa de câmbio real, maior é o saldo em conta-corrente do balanço de pagamentos e vice-versa (Figura 4). A base desta relação está no fato de que uma elevação da taxa de câmbio real aumenta o número de setores competitivos da economia, o que por sua vez aumenta a parcela de mercado das empresas domésticas tanto no mercado interno quanto no mercado externo ${ }^{8}$. Assim, uma apreciação excessiva do BRL pode gerar um aumento explosivo do déficit em conta-corrente, o que por sua vez aumenta a fragilidade externa da economia e prejudica o crescimento econômico no longo prazo. De acordo com essa visão, o ideal para a política macroeconômica seria ter sempre uma taxa de câmbio real elevada para manter a estabilidade do balanço de pagamentos e uma alta participação nas exportações mundiais.

\footnotetext{
${ }^{7} \mathrm{Na}$ literatura heterodoxa este conceito recebe o nome de "Stable Competitive Real Exchange rate" (Frenkel e Taylor 2006) ou "taxa de câmbio de equilíbrio industrial” (Bresser-Pereira 2007).

${ }^{8}$ No jargão de modelos de comércio exterior, as elasticidades renda e preço da economia dependem do valor da taxa de câmbio, o que por sua vez faz com que o saldo em conta-corrente, em \% do PIB, também seja uma função do valor da taxa de câmbio real. Para um modelo neste sentido, ver Ferrari et al. (2013).
} 


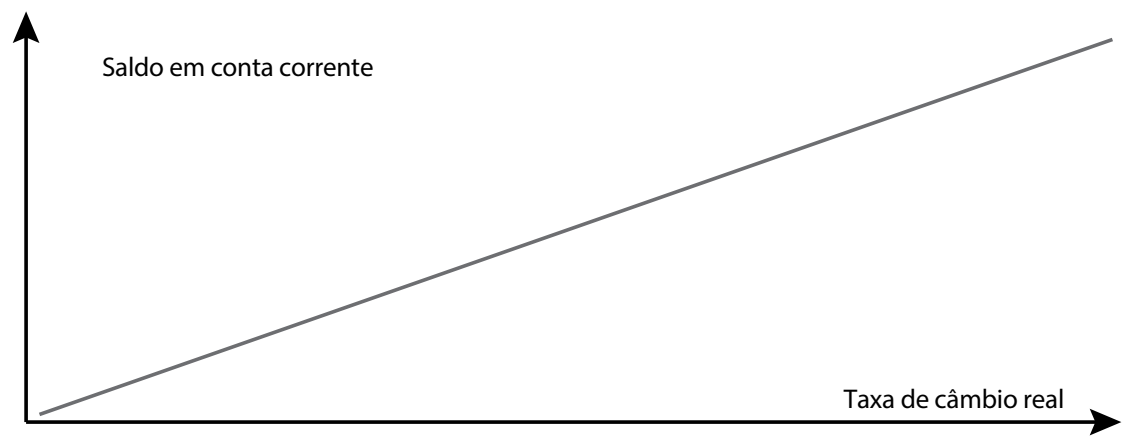

(ii) Câmbio e inflação: quanto menor a taxa de câmbio real, menor é a taxa de inflação e vice-versa (FIGURA 5) ${ }^{9}$. Essa relação está baseada em duas hipóteses bem intuitivas. De um lado, uma taxa de câmbio real elevada aumenta a proteção da economia nacional em relação a importações, o que faz com que choques de preços sejam transmitidos com mais intensidade nos setores de produtos comerciáveis (tradables). Do outro lado, uma taxa de câmbio elevada também reduz excessivamente o salário real e aumenta a intensidade do conflito distributivo para qualquer nível de taxa de desemprego ${ }^{10}$. Naturalmente, o raciocínio oposto se aplica no caso de uma taxa de câmbio baixa e, do ponto de vista da política macroeconômica, esta relação indica que o ideal é sempre ter uma taxa de câmbio real reduzida, ou seja, exatamente o oposto do que recomenda a estabilidade do balanço de pagamentos e a competitividade internacional.

Figura 5: Câmbio e Inflação

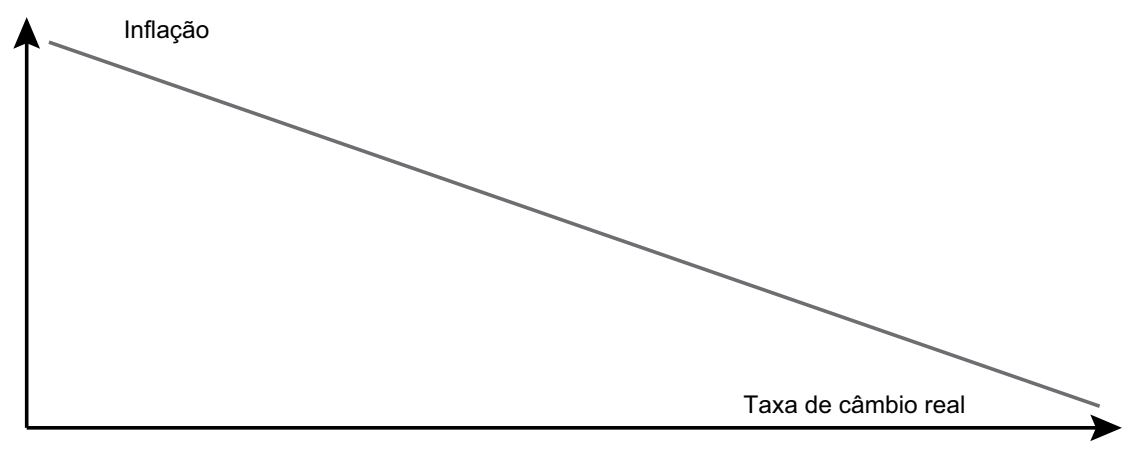

\footnotetext{
${ }^{9}$ Meus estudos econométricos sobre o Brasil (Barbosa Filho, 2010) indicam que pode haver uma não linearidade nesta relação, fazendo com que um mesmo valor de taxa de câmbio real seja consistente com mais de uma taxa de inflação no longo prazo.

${ }^{10}$ Esta relação pode ser justificada ou "microfundamentada" teoricamente por um modelo de determinação de preços sobre concorrência imperfeita, no qual as firmas buscam uma determinada taxa de lucro via mark-up variável. Para as bases de tal modelo, ver Barbosa Filho (2014a).
} 
(iii) Câmbio e crescimento: estudos econométricos do Brasil indicam que tanto uma taxa de câmbio muito elevada quanto uma taxa de câmbio muito reduzida são prejudiciais ao crescimento, isto é, existe uma relação não linear entre taxa de câmbio real e crescimento do PIB (Figura 6) ${ }^{11}$. Essa relação existe porque o câmbio tem dois impactos opostos sobre o investimento e, portanto, sobre o crescimento do produto potencial da economia. De um lado, uma elevação da taxa de câmbio aumenta a parcela dos lucros na renda e estimula o investimento. Do outro lado, uma elevação da taxa de câmbio também eleva o preço relativo do investimento e desestimula a acumulação de capital. O impacto final sobre o crescimento do produto potencial depende de qual efeito é mais intenso, o que por sua vez depende das condições iniciais da economia, isto é, do valor inicial da taxa de câmbio.

Figura 6: Câmbio e Crescimento

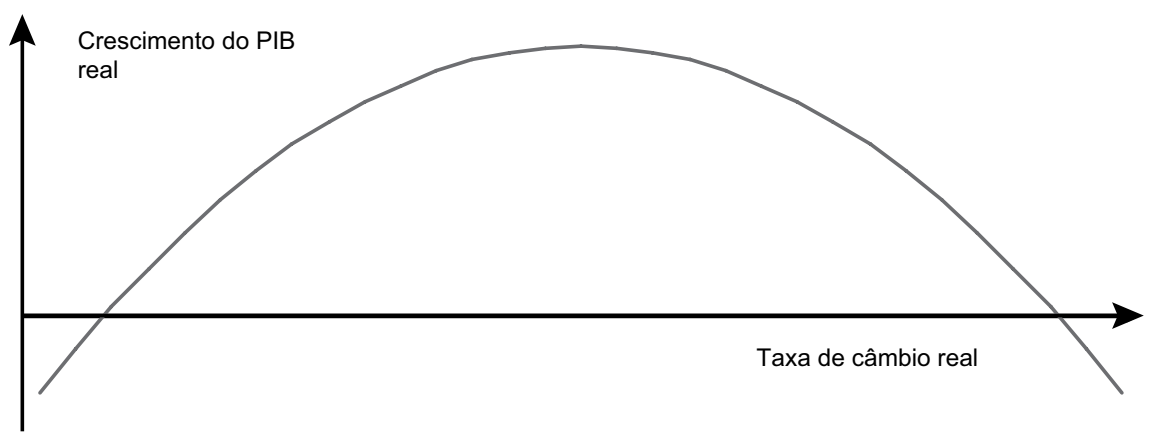

Com base nas três relações acima, é possível concluir que, pelo menos do ponto de vista teórico, o atual sistema de metas de inflação e câmbio flutuante é consistente com a estabilidade da taxa de câmbio real e do saldo em conta-corrente. Em outras palavras, ao definir o piso e o teto da meta de inflação, o governo acaba por estabelecer limites informais para a flutuação da taxa de câmbio, o que por sua vez estabelece limites para a flutuação do saldo em conta-corrente. Mais importante, ao estabelecer limites informais para flutuação cambial, o sistema de metas de inflação também acaba definindo limites para a flutuação da taxa de crescimento potencial da economia. O problema aparece quando passamos da teoria à prática, pois os efeitos de curto prazo de variações na taxa de câmbio criaram uma assimetria - o medo de depreciar - na forma com que a política monetária brasileira responde à taxa de câmbio, como mencionamos anteriormente.

Mesmo em um sistema de câmbio flutuante o governo pode e deve fazer operações cambiais para reduzir a volatilidade da taxa de câmbio, mas isso não deve impedir o ajuste da taxa de câmbio real às mudanças das condições domésticas e internacionais da economia. Sempre haverá uma linha tênue entre o que uns consideram "suavização" e outros consideram "controle de preços", mas a magnitude

\footnotetext{
${ }^{11}$ Para um modelo teórico e resultados econométricos desta relação, ver Barbosa Filho et al. (2011)
} 
das recentes operações cambiais do BCB, sobretudo quando comparada com o que a mesma instituição fez durante a crise de 2008 , indica que nossa autoridade monetária gastou muita munição muito antes do que seria necessário para apenas reduzir a volatilidade cambial. Vender um valor equivalente a $25 \%$ das reservas internacionais do país na forma de swaps cambiais quando a taxa de câmbio real simplesmente retornou à sua média de longo prazo foi excessivo e desnecessário. $\mathrm{O} \mathrm{BCB}$ deveria ter esperado mais antes de usar tamanho arsenal cambial.

As operações cambiais do BCB devem levar em conta não apenas os impactos de curto prazo da variação cambial, mas também os fundamentos da economia. $\mathrm{O}$ aumento do déficit em conta-corrente, o financiamento crescente deste déficit por capitais especulativos atraídos pelo carry trade, o alto custo unitário do trabalho em USD e a perda de competitividade internacional da economia brasileira indicam que ainda é necessário algum ajuste da taxa de câmbio real. O BCB pode e deve suavizar a velocidade deste ajuste, mas não deve se opor a este ajuste. No caso atual, isso significa reduzir gradualmente a posição vendida em swaps cambiais de nossa autoridade monetária nos próximos anos, de modo a deixar que a taxa de câmbio real se estabilize num patamar mais elevado, determinado pelo mercado.

Uma elevação adicional da taxa de câmbio real terá efeitos inflacionários no curto prazo, mas estes efeitos podem ser combatidos pelos mecanismos usuais de política monetária, como a taxa de juros e depósitos compulsórios. Além disso, o impacto inflacionário de uma elevação adicional da taxa de câmbio também pode ser compensado por outros instrumentos de política macroeconômica, como uma elevação do resultado primário do governo e outras ações estruturais que melhorem a produtividade e a eficiência da economia. Quanto melhor for a política fiscal e mais rápido for o crescimento da produtividade do trabalho, menos a taxa de câmbio terá que subir.

O desafio de acelerar o crescimento da produtividade será objeto de outros artigos e debates neste Fórum, logo não tratarei deste assunto aqui por limitação de tema e de espaço. Passemos, então, à questão fiscal.

\section{O DESAFIO FISCAL}

A desaceleração do crescimento da economia tem dificultado o cumprimento das metas fiscais do governo nos últimos anos. De um lado, a receita tem crescido lentamente devido ao menor crescimento do PIB e aos incentivos fiscais e tributários necessários para atenuar a perda de competitividade da indústria e incentivar o investimento. De outro lado, o gasto continuou a crescer acima do crescimento do PIB devido à ampliação da rede de proteção social via transferências de renda e ao aumento do gasto público com habitação, saúde e educação.

Em paralelo aos dois fatores mencionados acima, nos últimos dois anos a política fiscal também assumiu um papel maior de controle ou "suavização" dos reajustes em alguns preços monitorados - basicamente combustíveis e energia -, o que por sua vez reduziu ainda mais o resultado primário do governo federal. 
O aumento recente da restrição fiscal do governo significa que será necessário ajustar nossa política fiscal nos próximos anos. Não há espaço fiscal para aumentar os incentivos fiscais e financeiros ao setor produtivo - o "Estado Desenvolvimentista" - e continuar ampliando a rede de proteção social e serviços públicos universais - o "Estado do Bem-Estar Social”. Também não há espaço fiscal para o governo continuar a absorver o custo crescente da suavização de preços monitorados - o "Estado Intervencionista" - sem comprometer a estabilidade fiscal. Alguma coisa terá que ser ajustada e as demandas da população já indicaram a direção a seguir: preservar o Estado do Bem-Estar Social, ajustar o Estado Desenvolvimentista à nova realidade fiscal da economia e eliminar gradualmente os controles de preço. Este ajuste já começou, mas ainda há muito a ser feito nos próximos anos.

Para entender o tamanho do atual desafio fiscal vale a pena colocar nossa política fiscal recente em perspectiva histórica. A melhor maneira de fazer isso é analisar a evolução do resultado primário do governo federal sem receitas de concessões e operações patrimoniais (Figura 7) ${ }^{12}$. De acordo com tal conceito de "resultado primário ajustado", a política fiscal brasileira passou por cinco fases desde o final dos anos 1990:

Figura 7: Resultado primário da União em \% do PIB: resultado acima da linha e resultado excluindo operações com o Fundo Soberano do Brasil (FSB), Cessão Onerosa e Capitalização da Petrobras (COCP) e Concessões (CONC)

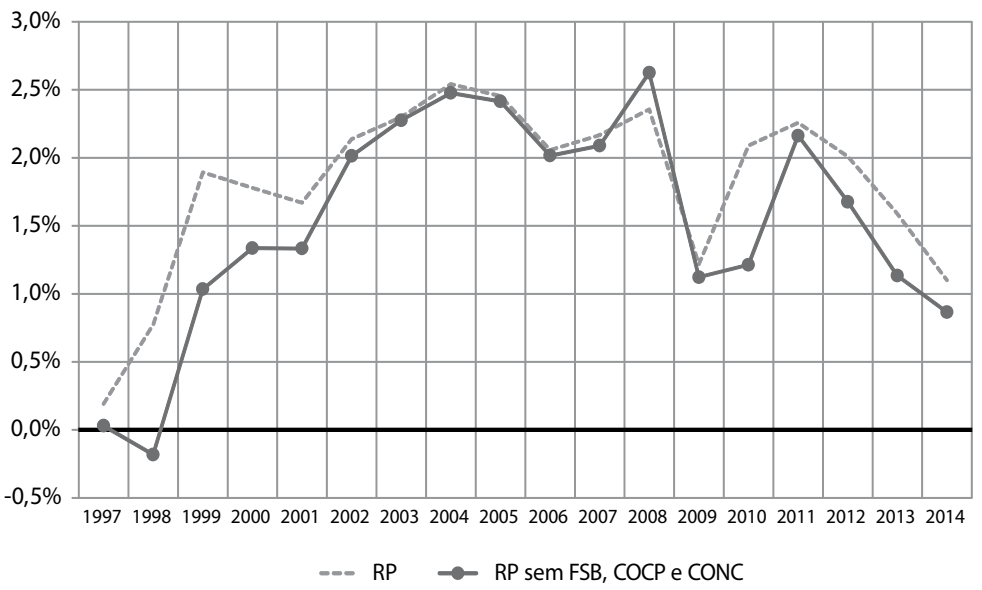

1) Primeiro ajuste fiscal com câmbio flutuante, em 1999-2001, quando o país adotou o atual regime de metas de inflação e de metas fiscais. O resultado primário ajustado do governo federal saiu de um déficit

\footnotetext{
${ }^{12}$ A exclusão de operações patrimoniais e de concessões se baseia na visão de que o governo nem sempre tem recursos no seu Fundo Soberano a sacar ou ativos a conceder. Em outras palavras, concessões e operações patrimoniais são itens não recorrentes do resultado primário e, como tal, eles devem ser utilizados preferencialmente para abater a dívida pública.
} 
de $0,2 \%$ do PIB, em 1998, para um superávit de 1,3\% do PIB, em 2001 (ajuste de 1,5\% do PIB em três anos).

2) Segundo ajuste fiscal com câmbio flutuante, em 2002-2004, quando o governo aumentou novamente seu resultado primário para combater os efeitos da depreciação do real e ajudar a política monetária no combate à inflação. Neste período, o resultado primário ajustado subiu de 1,3\% do PIB, em 2001, para 2,5\% do PIB, em 2004 (ajuste de $1,2 \%$ do PIB, novamente em três anos).

3) A expansão fiscal balanceada, em 2005-2008, quando a elevação dos preços das commodities no resto do mundo e a aceleração do crescimento da economia internamente aumentaram a renda disponível do Brasil e permitiram um aumento equilibrado das receitas e despesas primárias do Estado. Nesse período, o resultado primário ajustado do governo federal flutuou entre $2,0 \%$ e $2,5 \%$ do $\mathrm{PIB}^{13}$.

4) A expansão fiscal anticíclica, em 2009-2011, quando o governo inicialmente reduziu seu resultado primário para estimular a recuperação da economia, após a crise financeira internacional de 2008, mas depois elevou tal resultado rapidamente para retornar à situação pré-crise. Em números, o resultado primário ajustado caiu para $1,1 \%$ do PIB, em 2009, permaneceu praticamente no mesmo patamar em 2010, mas subiu rapidamente para 2,2\% do PIB em 2011 (um ajuste de 1,1\% do PIB em apenas um ano).

5) A expansão fiscal desbalanceada, desde 2012, quando o governo federal começou a ter dificuldades em cumprir suas metas fiscais devido à desaceleração do crescimento da economia e ao custo fiscal dos incentivos produtivos e do controle de preços monitorados. Até agora, essa fase registra uma forte queda do resultado fiscal ajustado do governo central, isto é, de 2,2\%, em 2011, para menos de $1,0 \%$ do PIB, em $2014^{14}$.

\footnotetext{
${ }^{13}$ Em 2005 houve um grande debate, dentro e fora do governo, sobre a necessidade de se promover mais um ajuste fiscal, o que seria o terceiro ajuste fiscal desde 1999, mediante uma "Política Fiscal de Longo Prazo". Como naquele momento a economia brasileira já havia experimentado dois ajustes fiscais sucessivos e a situação macroeconômica não indicava a necessidade de mais aperto, a opção do governo federal foi pela expansão fiscal equilibrada, o que por sua vez teve um impacto positivo sobre o crescimento do PIB devido ao que os economistas chamam de "Teorema do Orçamento Equilibrado" (Haveelmo, 1945). Para uma análise do debate econômico ao longo do governo Lula, ver Barbosa Filho e Souza (2010).

${ }^{14} \mathrm{Em} 2012$, o debate fiscal dentro e fora do governo girou em torno de duas opções: adotar metas fiscais ambiciosas, mas menos críveis, ou metas fiscais modestas, mas mais críveis. A opção do governo foi por metas ambiciosas, que infelizmente acabaram por não se materializar, mesmo após a adoção de sucessivas operações fiscais não recorrentes.
} 
Diante do quadro acima, o desafio fiscal do próximo governo é recuperar a capacidade de o Estado brasileiro produzir resultados primários recorrentes num nível adequado à manutenção da estabilidade fiscal, em um contexto no qual a sociedade brasileira tem demandas crescentes sobre o governo, mas no qual não é recomendável elevar a carga tributária para não prejudicar a competitividade internacional da economia. Esse desafio fiscal não se resume, portanto, a simplesmente aumentar o resultado primário em um ano. É preciso aumentar o resultado primário de forma duradoura, bem como fazer isso tanto com responsabilidade financeira - sem depender de operações não recorrentes - quanto com responsabilidade social — atendendo às demandas da população.

Frequentemente o debate fiscal mistura o tamanho do resultado primário com o tamanho do Estado. Os dois temas estão relacionados, mas não são a mesma coisa, pois é possível obter um mesmo resultado primário com diferentes tamanhos de Estado e vice-versa. Mais especificamente, do ponto de vista estritamente financeiro, o resultado primário do governo deve ser o valor necessário para manter a dívida líquida do setor público estável em \% do PIB, pois isso significa que o governo em exercício não está aumentando a necessidade de geração de superávits fiscais no futuro (a "regra de ouro" de política fiscal). No caso específico do Brasil, as atuais expectativas de crescimento da economia e de taxa de juros indicam que será necessário um resultado primário de 2,0\% a 2,5\% do PIB nos próximos anos, por parte de todas as esferas de governo, para manter a dívida líquida do setor público estável em proporção do PIB.

Para facilitar a exposição, considere que o governo brasileiro terá que voltar a produzir um resultado primário de $2 \%$ do PIB. Qual é o tamanho do Estado necessário para atingir tal esforço fiscal? A resposta depende do que a sociedade deseja do Estado. Por exemplo, um resultado primário de $2 \%$ do PIB pode ser obtido com uma receita primária de $20 \%$ do PIB e uma despesa primária de $18 \%$, ou com uma receita primária de $30 \%$ do PIB e uma despesa primária de $28 \%$ do PIB. Nos dois casos, o resultado primário é o mesmo e a estabilidade fiscal é mantida, mas o tamanho do Estado e seu impacto sobre a sociedade são completamente diferentes.

A responsabilidade fiscal significa um resultado primário recorrente no valor adequado para manter a estabilidade fiscal. O modo como tal resultado primário é obtido depende do tamanho do Estado que a sociedade deseja. Assim, em uma democracia como o Brasil, o tamanho da carga tributária deve ser compatível com a manutenção da estabilidade fiscal e com o atendimento das demandas da população sobre o Estado, o que por sua vez é determinado pelo resultado das eleições. Apesar de óbvio, esse ponto tem que ser ressaltado porque alguns analistas ainda encaram o tamanho da carga tributária como uma questão puramente técnica, como um problema somente de gestão. Melhorar a gestão e combater a corrupção é obrigação de qualquer governo, mas ainda assim o centro do debate orçamentá- 
rio é sempre como compatibilizar o desejo popular por mais serviços públicos com o desejo, também popular, de pagar menos tributos ${ }^{15}$.

Voltando ao desafio fiscal dos próximos anos, como a população brasileira não deseja e a competitividade da economia não recomenda uma elevação da carga tributária, o próximo governo terá que recuperar o resultado primário gradualmente para algo entre $2 \%$ e $2,5 \%$ do PIB com estabilidade de sua receita primária no patamar atual. A superação desse desafio passa por várias iniciativas, cada uma com prioridades e áreas orçamentárias específicas. Antes de passar a estas iniciativas, vale a pena analisar a despesa primária do governo federal por uma ótica econômica, isto é, por uma ótica que classifica as despesas primárias de acordo com sua função econômica. No caso do Brasil este tipo de análise implica dividir o gasto primário do governo federal em cinco grandes grupos de despesa:

1) Folha de pagamento: salários e benefícios do funcionalismo, incluindo ativos, aposentados e pensionistas.

2) Transferências de renda a indivíduos: transferências de recursos em dinheiro para as famílias na forma de Previdência Social, assistência social, Seguro Desemprego, abono salarial e Bolsa Família.

3) Subsídios e subvenções ampliadas: gasto fiscal do governo com incentivos financeiros à agricultura, exportações, infraestrutura, pequenas empresas e outros programas, acrescido do custo da desoneração da folha de pagamentos, dos subsídios à energia elétrica e dos incentivos financeiros à habitação popular (Minha Casa Minha Vida) ${ }^{16}$.

4) Investimentos: gasto direto do governo com o aumento de seu estoque de capital fixo.

5) Custeio: gasto fiscal que não se encaixa em nenhuma das categorias acima.

A classificação dos gastos do governo federal segundo a taxonomia (Tabelas 2 E 3) indica que o gasto primário aumentou em 3,3\% do PIB de 2002 a 2013, sendo a maior parte deste aumento concentrado nas transferências de renda a indivíduos ${ }^{17}$. Mais especificamente, os benefícios previdenciários aumentaram em

\footnotetext{
${ }^{15} \mathrm{E}$ isso não só no Brasil, como indica o levantamento recente do debate sobre o papel do Estado feito por Micklethwait e Wooldridge (2014). Para um levantamento mais técnico do crescimento do Estado em democracias ocidentais, ver Lindert (2004). Para um exemplo dos debates sobre tributação e papel do Estado, nos EUA, ver Weisman (2004).

${ }^{16}$ Eu classifico o programa Minha Casa Minha Vida como subsídio financeiro, pois ele representa um pagamento a um fundo financeiro (o FAR), para a construção de residências populares, ou subsídios diretos na entrada e nas taxas de juro em financiamentos com recursos do FGTS. Tal programa aumenta o investimento da economia como um todo, mas do ponto de vista contábil ele é um subsídio ao investimento residencial.
}

${ }^{17}$ O número para 2014 é o valor acumulado em 12 meses até julho de tal ano. 
Tabela 2: Evolução do gasto primário da União, em \% do PIB, sem capitalização da Petrobras

\begin{tabular}{|l|l|l|l|l|l|l|l|l|l|l|l|l|l|l|l|}
\hline & 2002 & 2003 & 2004 & 2005 & 2006 & 2007 & 2008 & 2009 & 2010 & 2011 & 2012 & 2013 & 2014 \\
\hline & 15,7 & 15,1 & 15,6 & 16,4 & 17,0 & 17,1 & 16,4 & 17,7 & 17,4 & 17,5 & 18,3 & 18,9 & 19,0 \\
\hline Despesa Primária & 4,8 & 4,5 & 4,3 & 4,3 & 4,5 & 4,4 & 4,3 & 4,7 & 4,4 & 4,3 & 4,2 & 4,2 & 4,2 \\
\hline Pessoal & & & & & & & & & \\
\hline
\end{tabular}

Fonte: IBRE/FGV, os dados de 2014 representam o valor acumulado em 12 meses até julho

Tabela 3: Variação do gasto primário da União, em \% do PIB, sem capitalização da Petrobras

\begin{tabular}{|c|c|c|c|c|}
\hline & $\begin{array}{c}\text { PT } \\
2003-14\end{array}$ & $\begin{array}{c}\text { Lula } 1 \\
2003-06\end{array}$ & $\begin{array}{c}\text { Lula } 2 \\
2007-10\end{array}$ & $\begin{array}{c}\text { Dilma } \\
\text { 2011-14 }\end{array}$ \\
\hline Despesa Primária & $\underline{3,3}$ & $\underline{1,2}$ & $\underline{0,5}$ & $\underline{1,6}$ \\
\hline Pessoal & $\underline{-0,6}$ & $\underline{-0,4}$ & $\underline{0,0}$ & $\underline{-0,2}$ \\
\hline Transferências de renda & $\underline{2,7}$ & $\underline{2,0}$ & $\underline{0,1}$ & $\underline{0,6}$ \\
\hline Previdência Social & 1,4 & 1,3 & $-0,2$ & 0,3 \\
\hline Demais programas & 1,3 & 0,7 & 0,3 & 0,3 \\
\hline Subsídios e subvenções ampliados & $\underline{0,9}$ & $\underline{0,2}$ & $\underline{-0,1}$ & $\underline{0,8}$ \\
\hline Custeio ajustado & $\underline{0,1}$ & $\underline{-0,4}$ & $\underline{0,2}$ & $\underline{0,3}$ \\
\hline Saúde & 0,2 & 0,0 & 0,0 & 0,2 \\
\hline Educação & 0,4 & $-0,1$ & 0,2 & 0,2 \\
\hline Demais Ministérios & $-0,5$ & $-0,3$ & $-0,1$ & $-0,1$ \\
\hline Investimento (sem MCMV) & $\underline{0,3}$ & $\underline{-0,2}$ & $\underline{0,4}$ & $\underline{0,1}$ \\
\hline
\end{tabular}

Fonte: IBRE/FGV, os dados de 2014 representam o valor acumulado em 12 meses até julho 
1,4\% do PIB entre 2002 e 2014, enquanto as demais transferências de renda aumentaram em 1,3\% do PIB, sobretudo devido à expansão da assistência social aos idosos (LOAS) e aos mais pobres (Bolsa Família). Em contraste com essa elevação, o gasto federal com funcionalismo caiu em $0,6 \%$ do PIB no mesmo período, sendo esta queda concentrada no primeiro mandato do Presidente Lula e no atual governo.

Passando para as demais despesas, o gasto federal com subsídios e subvenções ampliadas aumentou em 0,9\% do PIB de 2002 a 2014, mas a maior parte deste aumento se concentrou no governo atual. Esse aumento decorre do maior gasto recente com subsídios à energia elétrica, desoneração da folha de pagamento das empresas, e o programa Minha Casa Minha Vida. Como mencionei anteriormente, a apreciação cambial no início do governo Dilma, bem como a suavização dos reajustes de preços monitorados num contexto de choques adversos absorveram uma parte substancial do resultado primário nos últimos anos.

Já do lado do investimento público propriamente dito, houve um aumento de apenas $0,3 \%$ do PIB de 2002 a 2014, uma vez que a maior parte do gasto federal nesta área está sendo feito via concessões de infraestrutura ao setor privado. Também cabe ressaltar que o aumento do investimento público teve fases distintas, isto é: uma queda de $0,2 \%$ no primeiro governo Lula (durante o já mencionado "segundo ajuste fiscal"), um aumento de $0,4 \%$ no segundo governo Lula (com o lançamento do "PAC 1 ") e um aumento de $0,1 \%$ no governo atual (com a transição para o "PAC 2").

Por fim, do lado do custeio, houve um aumento de apenas $0,1 \%$ do PIB entre 2002 e 2014, basicamente devido à expansão do gasto federal com saúde e educação, que subiram em $0,2 \%$ e $0,4 \%$ do PIB, respectivamente. O gasto com custeio dos demais ministérios caiu em $0,5 \%$ do PIB no mesmo período, o que por sua vez indica um forte contingenciamento de gastos "não prioritários" desde 2003.

Considerando todos os números, a conclusão geral é que, nos últimos 12 anos, os governos do Partido dos Trabalhadores (PT) têm privilegiado a construção e ampliação do Estado do Bem-Estar Social no Brasil. Este movimento começou já em 2003, pelo aumento do gasto federal com transferências de renda, e se acelerou a partir de 2006, com o aumento do gasto federal com educação e saúde públicas.

Olhando à frente, o desafio fiscal de 2015-2018 envolve ações tanto do lado do orçamento primário quanto do orçamento financeiro do governo federal, uma vez que o custo de carregamento dos créditos do governo junto às instituições financeiras oficiais também tem pressionado a dívida líquida do setor público para cima nos últimos anos.

A política fiscal do próximo governo também deve dar continuidade ao processo de desenvolvimento social iniciado na última década, sobretudo na ampliação de serviços públicos de educação, saúde e segurança, bem como dos investimentos públicos em desenvolvimento urbano e inclusão digital. Além disso, será necessário compatibilizar o esforço fiscal com a simplificação e desburocratização tributária, de modo a aumentar a competitividade da economia e estimular o investimento e a produção. E, obviamente, todas essas iniciativas deverão ser executadas com 
aumento da transparência e prestação de contas fiscais à sociedade, de modo que fique cada vez mais claro o quanto cada desoneração, programa ou incentivo público custa e rende ao país.

Com base na visão acima, e para concluir este artigo, resta apresentar minha sugestão de principais ações estruturais do lado fiscal para superar os problemas atuais. Como a política fiscal envolve várias esferas, qualquer lista inclui vários itens e atores políticos e sociais. Para facilitar a exposição, as principais ações podem ser agrupadas em doze metas ou "trabalhos fiscais". Vejamos cada um separadamente:

1) Diminuir a perda fiscal com o controle de preços monitorados: a suavização dos reajustes dos preços dos combustíveis tem representado uma grande perda de receita primária para o governo nos últimos anos. Esta perda inclui tanto a desoneração da CIDE combustível quanto os dividendos e a tributação direta que a Petrobras deixa de pagar à União por ter um resultado menor do que ocorreria com preços mais alinhados à realidade do mercado. Além do impacto federal, também há o lento crescimento da arrecadação estadual de ICMS sobre combustíveis. No mesmo sentido, o subsídio ao preço da energia elétrica consumiu um valor considerável de recursos fiscais em 2013 e 2014, quando o governo federal absorveu parte dos efeitos da seca e dos custos de transição para as novas tarifas de energia elétrica. A normalização de preços, tanto de combustíveis quanto de energia, irá gradualmente elevar o resultado primário do governo nos próximos anos. Os reajustes dos preços da energia já começaram e devem prosseguir em 2015-2018, como já foi anunciado pelo governo atual. O reajuste dos preços dos combustíveis também deve prosseguir, de acordo com o custo de produção e a margem de lucro necessária para manutenção da estabilidade patrimonial e dos investimentos da Petrobras, como também já foi anunciado pela direção da companhia.

2) Continuar a reduzir a folha de pagamento da União em proporção do PIB: a União já vem reduzindo seu gasto com funcionalismo em \% do PIB mesmo no contexto de desaceleração do PIB, o que deve ser mantido nos próximos anos, isto é, o governo deve realizar um novo acordo plurianual com o funcionalismo no qual o crescimento da folha de pagamento da União, incluindo aposentados e pensionistas, não ultrapasse o crescimento do PIB nominal. Esse tipo de iniciativa pode e deve ser transformada em Lei Complementar, de modo a criar um teto para o crescimento da folha de pagamentos da União por um período mínimo de quatro anos. Já há uma proposta neste sentido no Congresso Nacional, enviada ainda pelo Presidente Lula. Caberá ao próximo governo retomar as discussões. 
3) Estabilizar as transferências de renda a indivíduos em proporção do PIB: como já foi mencionado, as transferências de renda aumentaram substancialmente em \% do PIB nos últimos anos, uma vez que o governo corretamente manteve a expansão de seus programas sociais mesmo em um contexto de desaceleração do PIB. O desafio dos próximos anos é alinhar o crescimento de tais programas ao novo ritmo de crescimento da economia, o que implica reavaliar as regras de concessão de novos benefícios, tanto por parte da Previdência Social quanto por parte dos programas do FAT, que são os principais itens de transferência de renda. Do lado da Previdência, as iniciativas incluem a continuação dos aumentos reais - mas num ritmo mais moderado - do salário mínimo ${ }^{18}$, bem como a retomada do Fórum da Previdência Social para discutir as diversas alternativas de sustentabilidade das despesas do INSS no longo prazo ${ }^{19}$. Do lado do FAT, a principal iniciativa é uma reforma do programa de abono salarial, de modo a abrir espaço para a continuação do crescimento das demais transferências de renda às famílias, sobretudo do salário mínimo.

4) Ampliar o gasto público real com saúde e educação, por habitante: o gasto público federal com custeio em saúde e educação já vem subindo nos últimos anos e isso deve ser mantido. Porém, ao invés de usar somente o PIB como base de comparação, é necessário mudar a sistemática para metas de crescimento do gasto real por habitante, juntamente com metas de aumento da qualidade e melhor distribuição regional dos serviços. Com a recuperação do crescimento da economia, é perfeitamente possível aumentar rapidamente o gasto público per capita com saúde e educação e combinar isso com melhores serviços, sobretudo via melhor gestão e maior utilização de tecnologias de informação e comunicação (TIC) por parte do setor público.

5) Reduzir os demais gastos com custeio em \% do PIB: o gasto com custeio do governo federal tem se mantido em torno de $1 \%$ do PIB nos últimos anos, quando excluímos saúde e educação da conta. Esse gasto deve ser reduzido nos próximos anos, sobretudo via melhor gestão dos sistemas de compras e administração pública (pregão eletrônico). Também há grande potencial de melhorias com a

\footnotetext{
${ }^{18}$ Para uma proposta neste sentido, ver Barbosa Filho e Pires (2014).

${ }^{19}$ A aceleração do crescimento da população idosa torna necessário retomar as discussões sobre Previdência. Quanto mais cedo o sistema for ajustado à nova realidade econômica e populacional do Brasil, mais gradual será o ajuste. Como o Brasil ainda tem grandes ganhos de produtividade a serem explorados, ainda é perfeitamente possível sustentar o aumento do nível de renda per capita de todos mesmo com o aumento da participação de idosos na população como um todo. Em outras palavras, o problema da Previdência é mais distributivo do que produtivo.
} 
adoção de novas técnicas de gestão patrimonial via parcerias público-privadas na construção e administração de imóveis públicos, bem como pelo uso mais generalizado de tecnologias de informação e comunicação no atendimento à população (governo eletrônico).

6) Aumentar o investimento público em desenvolvimento urbano e inclusão digital: o investimento público permaneceu relativamente estável em \% do PIB nos últimos anos. Dado que a maior parte do investimento em infraestrutura econômica do país (energia, transporte e logística) já está sendo implementada via concessões, o investimento público via Orçamento Geral da União (OGU) deve se direcionar crescentemente para áreas de maior interesse social áreas onde a taxa de retorno social excede a taxa de retorno privado. Os principais candidatos para receber mais recursos públicos nos próximos anos são o desenvolvimento urbano, sobretudo transporte público em parceria com estados e municípios, e a inclusão digital, na forma de serviços de banda larga rápida e barata para a população de menor renda. Cabe ressaltar que estas duas iniciativas já estão em andamento pelo governo atual e devem ser continuadas nos próximos anos.

7) Reduzir o custo de carregamento dos créditos da União junto aos bancos públicos: atualmente os empréstimos da União às instituições financeiras oficiais (IFOs) têm um custo financeiro de aproximadamente $0,6 \%$ do PIB por ano. A redução desse custo tem o mesmo efeito fiscal de uma elevação do resultado primário, uma vez que ela reduz a velocidade de crescimento da dívida líquida do setor público ${ }^{20}$. O caminho para reduzir esse custo financeiro passa necessariamente por duas iniciativas: reduzir o volume de novos empréstimos aos bancos públicos - como já começou a ser feito pelo governo atual - e aumentar gradualmente a TJLP, para reduzir a diferença entre as taxas de captação e aplicação dos recursos públicos utilizados no crédito direcionado, sobretudo via BNDES. O subsídio financeiro ao investimento em infraestrutura ainda é necessário, mas ele pode ser reduzido sem comprometer a viabilidade dos investimentos se tal iniciativa for parte de um conjunto de medidas que recupere o crescimento da economia ${ }^{21}$.

\footnotetext{
${ }^{20}$ Para uma análise contábil deste ponto, ver Barbosa Filho (2014b).

${ }^{21}$ Para uma proposta sobre a TJLP, ver Barbosa Filho (2014c). Sobre este ponto vale acrescentar que, entre crescimento e incentivo financeiro, o crescimento é geralmente mais importante para decisão privada do investimento. Assim, de pouco adianta oferecer incentivos financeiros quando o custo fiscal destes incentivos aumenta a dívida pública e requer um ajuste fiscal permanente que prejudica o próprio crescimento da economia.
} 
8) Reduzir custo das dívidas dos estados e municípios: o governo atual já encaminhou proposta de redução do custo das dívidas de estados e municípios junto à União para os pagamentos restantes dos contratos vigentes. Essa iniciativa não foi à frente devido à demanda, por parte de alguns estados e municípios, de um perdão excessivo em seus débitos junto à União. A solução do impasse passa por uma negociação na qual o custo da dívida seja reduzido em troca de investimentos autorizados e monitorados pela União, sem comprometer a estabilidade fiscal do país. O custo financeiro da dívida pode ser reduzido, mas as restrições e condições administrativas impostas aos estados devem ser aumentadas substancialmente para garantir que os recursos liberados por tal iniciativa sejam utilizados de modo consistente com a manutenção da estabilidade fiscal.

9) Realizar reforma do PIS/COFINS com neutralidade fiscal: a complexidade da carga tributária brasileira é hoje um fator de perda de competitividade das empresas tão importante quanto a taxa de câmbio e o preço da energia. Uma das iniciativas para diminuir custo tributário das empresas e do próprio governo é reformar o principal tributo indireto federal, o PIS/COFINS, fazendo com que toda a aquisição de insumos gere créditos tributários para as empresas. Esta reforma deve ser adotada em conjunto com uma grande simplificação das regras, isto é, com uma reavaliação dos diversos regimes especiais de tributação de PIS/COFINS existentes na economia. Devido à restrição fiscal do governo, essa reforma também deve ser neutra do ponto de vista da arrecadação, ou seja, não deve ocorrer redução de receita para o governo.

10) Completar reforma do ICMS sem redução do resultado primário: o governo já realizou a reforma do ICMS sobre importações e encaminhou sua proposta de reforma do ICMS interestadual sobre as demais transações. A maioria dos estados brasileiros já chegou a um consenso sobre a validação dos incentivos fiscais existentes, bem como sobre a redução gradual das alíquotas interestaduais no médio prazo $^{22}$. Diante deste quadro, o próximo governo pode completar a reforma do ICMS com adoção de um cronograma de transição para o novo sistema que não ameace o equilíbrio fiscal do país no curto prazo, mas que elimine a ineficiência e a incerteza sobre a tributação estadual.

${ }^{22}$ Ver Convênio CONFAZ ICMS número 70, de 2014, que foi aprovado por 21 das 27 unidades da federação brasileira. Os estados do Amazonas, Ceará, Espírito Santo, Goiás, Rio Grande do Norte e Santa Catarina não aderiram a tal Convênio. 
11) Estimular o empreendedorismo: o governo atual já decidiu ampliar o sistema de tributação preferencial de micro e pequenas empresas, o SUPERSIMPLES, a todos os setores da economia. Essa iniciativa deve começar já em 2015, mas a estrutura do atual sistema ainda inibe o crescimento das empresas a partir de uma determinada faixa de faturamento. Para superar esta barreira e estimular o empreendedorismo no Brasil, é necessário criar uma progressão mais suave da tributação dentro do SUPERSIMPLES, bem como criar uma "faixa de saída" de tal sistema para o regime de tributação do lucro presumido. Essa iniciativa já está sendo analisada pelo governo atual e, se possível, ela simplificará a estrutura tributária e incentivará o crescimento das empresas brasileiras, o que por sua vez contribuirá para o aumento da formalização e da produtividade da economia. Porém, devido à restrição fiscal do governo no curto prazo, qualquer aperfeiçoamento do SUPERSIMPLES também deve ser neutro do ponto de vista da arrecadação de impostos.

12) Aumentar a transparência fiscal, sobretudo do gasto tributário do governo: o Brasil já possui um sistema bem transparente de acompanhamento do gasto público. As contas do governo federal são transparentes e acompanhadas em detalhe pelos órgãos de controle. No âmbito do próprio Poder Executivo, o Portal da Transparência da Controladoria Geral da União (CGU) publica os dados das transferências de renda, salários do funcionalismo e outros programas de governo com identificação de quem recebeu os recursos. Essa mesma iniciativa pode e deve ser ampliada para outras esferas de atuação do governo, sobretudo para as desonerações e incentivos fiscais nos quais o agente beneficiado pode optar por receber ou não o benefí$\mathrm{cio}^{23}$, o que permitirá o melhor acompanhamento dos diversos incentivos do governo à produção, permitindo um melhor cálculo de custo e benefício de cada programa.

A lista acima não é obviamente exaustiva, mas em política fiscal dificilmente é possível resolver tudo ao mesmo tempo. A arte da política fiscal no Brasil ou em qualquer democracia é compatibilizar demandas aparentemente inconsistentes num arranjo compatível com a estabilidade da carga tributária e da dívida pública em $\%$ do PIB. Essa tarefa é muito mais política do que técnica, isto é, os economistas podem ajudar a calcular os custos e benefícios de cada escolha, mas os políticos têm o papel fundamental de construir o apoio da maioria em torno de uma estratégia econômica de crescimento com distribuição de renda. Estratégias econômicas somente de crescimento não são viáveis, pois a redução da desigualdade é tanto um meio quanto um objetivo da ação do Estado numa democracia. Estratégias

\footnotetext{
${ }^{23}$ Para uma proposta formal neste sentido, ver Barbosa Filho (2014d).
} 
econômicas somente de distribuição de renda também não são viáveis, pois sem crescimento não é possível atender às demandas da população num país de renda

média como o Brasil. Nesse sentido, o maior desafio do próximo governo é político e não econômico: manter o consenso nacional em torno de uma política que recupere o crescimento da economia e continue o modelo de desenvolvimento para todos iniciado na última década.

\section{REFERÊNCIAS BIBLIOGRÁFICAS}

Barbosa Filho, N.H. (2010), “Duas não linearidades e uma assimetria.” Artigo apresentado no $7^{\circ}$ Fórum de Economia da Escola de Economia de São Paulo.

Barbosa Filho, N.H. (2012). “Dez anos de política econômica.” Em Sader, E. (org) 10 anos de governos pós-neoliberais no Brasil: Lula e Dilma

Barbosa Filho, N.H. (2014A). “A Structuralist Inflation Curve,” Metroeconomica, Volume 65, Issue 2, pages 349-376.

Barbosa Filho, N.H. (2014B). “Resultado Primário, Dívida Líquida e Dívida Bruta: Um Modelo Contábil”, a ser publicado no livro Ensaios IBRE 2014, disponível em: http://brasildebate.com.br/ uma-proposta-de-ajuste-de-medio-prazo-da-tjlp/.

Barbosa Filho, N.H. (2014C). “Uma proposta de ajuste de médio prazo da TJLP”. Disponível em: http://brasildebate.com.br/uma-proposta-de-ajuste-de-medio-prazo-da-tjlp/.

Barbosa Filho, N.H. (2014D). “Uma Proposta de Transparência Tributária”. Disponível em: http:// brasildebate.com.br/uma-proposta-de-transp-tributaria/.

Barbosa Filho, N.H e Pires, M.C. (2014). "Impacto fiscal de regras alternativas de reajuste do salário mínimo no Brasil,” Texto Apresentado no Seminário: Política de Salário Mínimo para 20152018: Avaliações de Impacto Econômico e Social, IBRE e EESP/FGV.

Barbosa Filho, N.; Souza J. A. P. (2010) A inflexão do governo Lula: política econômica, crescimento e distribuição de renda. In: Sader, E; Garcia, M. A. (orgs.) Brasil: entre o Passado e o Futuro. São Paulo: Editora Fundação Perseu Abramo/Boitempo.

Barbosa Filho, N.H., Silva, J.A., Goto, F. and Silva. B. (2011). "Crescimento econômico, acumulação de capital e taxa de câmbio,” in: Holland, M. and Nakano, Y. (ogs), Taxa de Câmbio no Brasil: Estudos de uma perspectiva do desenvolvimento econômico, São Paulo: Elsevier.

Bresser-Pereira, L.C. (2007). Macroeconomia da Estagnação. São Paulo: Editora 34.

Calvo. G. e Reinhart, C. (2010). The Fear of Floating, NBER Working Paper 7993.

Ferrari, M.A., Freitas, F.N.P. e Barbosa-Filho, N.H. (2013). "A taxa de câmbio real e a restrição externa: uma proposta de releitura com elasticidades endógenas,” Rev. Econ. Polit. vol.33 no.1.

Frenkel, R. and Taylor, L. (2006). Real Exchange Rate, Monetary Policy and Employment, DESA Working Paper No. 19

Giambiagi, F. e Schwartzman, A. (2014). Complacência. Rio de Janeiro: Campus.

Haavelmo, T. (1945). "Multiplier Effects of a Balanced Budget", Econometrica, Vol. 13, No. 4, Oct., 1945.

Lindert, P. (2004). Growing Public: The Story: Social Spending and Economic Growth since the Eighteenth Century

Micklethwait, J. e Wooldridge, A. (2014). The Fourth Revolution: The Global Race to Reinvent the State.

Weisman, S.R. (2004). The Great Tax Wars: Lincoln--Teddy Roosevelt--Wilson How the Income Tax Transformed America 